\title{
Experiências vivenciadas no Programa Residência Pedagógica em uma Escola Municipal de Ensino Fundamental de São Vicente
}

\author{
Experiences lived in the Pedagogical Residence Program in a Municipal \\ Elementary School in São Vicente \\ Mariana Costa Gama \\ Lívia Solange Nery da Silveira \\ Mariangela Camba \\ Elisete Gomes Natário \\ Michel da Costa \\ Cristina Celia Neri Borges
}

[...] quem forma se forma e re-forma ao formar e quem é formado formase e forma ao ser formado. (FREIRE,1996, p.12)

Resumo: Este relato de experiência apresenta a vivência de acadêmicos de um curso de Licenciatura em Educação Física em um Programa de Residência Pedagógica (PRP), financiado pela CAPES, realizado entre o período de agosto de 2018 a janeiro de 2020, em uma escola pública de São Vicente, no litoral paulista. O texto apresenta aspectos gerais do desenvolvimento das atividades realizadas e resultados obtidos, do Programa a partir da visão das residentes. O objetivo deste trabalho é explicitar, na visão dos residentes do PRP, a percepção da realidade no ambiente educacional, suas experiências de auxiliar docência na escola-campo e como perceberam a formação teórica se retratando na prática. A metodologia desenvolvida é desenvolvida a partir das narrativas dos residentes, registradas em diferentes momentos da realização do subprojeto, ancorada nos princípios de Creswell (2014) e Bruner (2002). Os principais resultados dessa experiência da Regência Pedagógica passam, necessariamente, pela própria vivência da prática da docência, isto é, lidar com a realidade das crianças, da escola, dos pares - equipe - e aprender a lidar com as inseguranças e dificuldades frente a pouca experiência nessa área.

Palavras-chave: Programa de Residência Pedagógica. Formação de Professores. Estágio. Projetos em Educação Física.

Abstract: This experience report presents the experience of students of a Physical Education Degree course in a Pedagogical Residency Program (PRP), financed by CAPES, carried out between August 2018 and January 2020, at a public school in São Vicente, on the coast of São Paulo. The text presents general aspects of the development of the activities carried out and results obtained, from the Program from the residents' point of view. The objective of this work is to explain, in the view of the residents of PRP, the perception of reality in the educational environment, their experiences of assisting teaching in the field school and how they perceived the theoretical training portrayed in practice. The methodology developed is developed from the residents' narratives, recorded at different times of the subproject, based on the principles of Creswell (2014) and Bruner (2002). The main results of this pedagogical conduct experience are necessarily related to the teaching experience, 
that is, dealing with the reality of children, school, peers - team - and learning to deal with insecurities and difficulties in the face of little experience in that area.

Keywords: Pedagogical Residency Program. Teacher training. Stage. Physical Education Project.

\section{Introdução}

Este relato de experiência apresenta a vivência de acadêmicos de um curso de Licenciatura em Educação Física em um Programa Residência Pedagógica (PRP), realizado entre o período de agosto de 2018 a janeiro de 2020. Procuramos nesse texto apresentar aspectos gerais do desenvolvimento das atividades realizadas e resultados obtidos de maneira ampla, isto é, do Programa como um todo, a partir da visão dos residentes.

O objetivo deste trabalho é mostrar, na visão dos residentes do PRP, a percepção da realidade no ambiente educacional, suas experiências de auxiliar docência na escola-campo e como perceberam a formação teórica se retratando na prática.

O Programa, elaborado e financiado pela Coordenação de Aperfeiçoamento de Pessoal de Nível Superior (CAPES), foi desenvolvido em uma escola municipal de ensino fundamental de São Vicente - SP e acompanhado por uma professora preceptora regente na escola-campo e pelos docentes orientadores da Universidade, onde os residentes estudam

O grupo de residentes foi formado por quinze alunos do Curso de Licenciatura em Educação Física da Faculdade de Educação Física da Universidade Metropolitana de Santos. O Programa da Residência Pedagógica visou o aperfeiçoamento da formação dos residentes; induzir a reformulação do estágio supervisionado baseando-se na experiência do Programa; fortalecer, ampliar e consolidar a relação entre a Universidade e a escola e promover a adequação dos currículos e propostas pedagógicas de acordo com a Base Nacional Comum Curricular - BNCC (BRASIL, 2018). Para uma melhor organização e planejamento das ações pedagógicas do Programa, foi dividido em cinco etapas, sendo: grupo de formação dos residentes na Universidade; ambientação na escola-campo; regência; avaliação e socialização. 
Os autores do relato são duas licenciadas do curso de Educação Física, participantes como residentes, dois professores-coordenadores do subprojeto na Universidade, a coordenadora institucional e a professora-preceptora dos residentes em uma escola de ensino fundamental. Ressaltamos que o financiamento do Programa foi da parceria da Coordenação de Aperfeiçoamento de Pessoal de Nível Superior (CAPES) e da Universidade Metropolitana de Santos - UNIMES.

\section{Programa de Residência Pedagógica na Universidade Metropolitana de Santos}

Nos modelos de formação inicial de professores no Brasil temos a presença dos estágios curriculares obrigatórios, realizados em escolas de educação básica, e as práticas previstas como componente curricular, vivenciadas ao longo do curso nas licenciaturas. A obrigatoriedade dos estágios curriculares e demais dispositivos voltados para a formação prática ao longo dos cursos pressupõe a existência de uma formação que busca a interação entre as atividades práticas e a reflexão teórica sobre elas.

No entanto, não há no atual modelo de estágio curricular a efetivação de processo de aprendizagem prática em que os estudantes possam ser protagonistas de sua própria formação, há um distanciamento entre a universidade e os cenários de atuação profissional.

Gatti e Nunes (2009) constataram que os conteúdos das disciplinas a serem ofertados na Educação Básica de metodologias e de práticas de ensino apareciam de forma rara e reduzida nos cursos de pedagogia e eram apresentados de forma genérica ou superficial, o que indicava haver pouca associação com as práticas docentes e que a mediação entre teoria e prática não ocorria.

Em relação aos demais cursos de licenciaturas analisados, o panorama era quase o mesmo, pois na grande maioria das ementas analisadas não foi observada articulação entre as disciplinas de formação específica (conteúdos da área disciplinar) e a formação pedagógica, sendo que esta ocupava lugar 
secundário em todos os cursos examinados. Isto confirma a existência de um hiato entre a universidade e a escola, nos modelos tradicionais de estágio.

Gatti (2010) destaca que é no início da docência que o licenciado vivencia a experiência do ensino, uma vez que ele assume a responsabilidade da sala de aula. De acordo com a pesquisadora, corresponde a uma etapa muito importante para a aquisição de competências e para a iniciação nas rotinas de trabalho que acompanharão o profissional ao longo de sua carreira, compondo a estrutura da prática profissional.

O Programa de Residência Pedagógica (PRP) da Universidade Metropolitana de Santos - UNIMES esteve no período desse estudo vinculado aos Cursos de Licenciatura em História, Geografia, Matemática, Educação Física e Pedagogia, tendo como objetivo geral aperfeiçoar a formação dos discentes dos cursos de licenciaturas da Universidade por meio do desenvolvimento de projetos que fortalecessem o campo da prática e conduzissem o licenciando a exercitar de forma ativa a relação entre teoria e prática profissional docente.

O programa articulou cenários variados de aprendizagem prática dos pedagogos em formação e de alunos de outras licenciaturas que participaram do Programa, como os cursos de Educação Física, Matemática, História e Geografia, buscando vincular a formação inicial, realizada no lócus universitário e formação continuada de professores de escolas públicas participantes do Programa, a partir da cooperação mútua das instituições.

O Programa de Residência Pedagógica da UNIMES ocorreu a partir de dois subprojetos: "1- Aprendendo e ensinando significativamente entrelaçando saberes e fazeres" (subprojeto das Licenciaturas em Geografia, História, Matemática e Pedagogia) e "2 - Relações e inter-relações - diálogo e intervenções do professor em formação" (subprojeto do Curso de Licenciatura em Educação Física). Ambos subprojetos viabilizaram a proposta do PRP que foi a aprendizagem prática que ocorreu por meio da imersão dos residentes estagiários - em vivências sistemáticas e temporárias nas práticas pedagógicas de docentes profissionais, acompanhadas pela orientação de um preceptor - 
professor da escola-campo - e do professor coordenador - docente da universidade, considerados como parceiros no processo de formação inicial.

Os autores desse relato participaram do Subprojeto 2, motivo pelo qual, iremos nos debruçar apenas com foco nesse, apesar de em alguns momentos, falarmos do projeto institucional.

Entendemos que o Programa de Residência Pedagógica possibilitou um campo de conhecimento mútuo entre a Instituição de Ensino Superior e a Unidade de Ensino. O contato permanente da universidade com a escola, por meio da presença dos residentes e das preceptoras que nos orientaram e que participaram da formação continuada oferecida na IES foi revelando um conjunto de questões a serem investigadas. Tais como: o cotidiano do trabalho do professor em sala de aula, a coordenação do trabalho pedagógico compreendida a partir de pontos de vista plurais, a comunidade local, a integração teoria a prática.

O Projeto Institucional de Residência Pedagógica da UNIMES teve duração de dezoito meses, distribuídos da seguinte forma:

- 2 meses para o curso de formação de preceptores e preparação dos alunos para o início das atividades da residência pedagógica;

- 4 meses de orientação conjunta (docente orientador e preceptor) com ambientação do residente na escola e elaboração do Plano de Atividade do residente, devendo o residente cumprir o mínimo de 60 horas na escola-campo;

- 10 meses para a realização de 320 horas de imersão na escola, sendo no mínimo 100 horas destinadas à regência de classe, que incluiu o planejamento e execução de pelo menos uma intervenção pedagógica específica, da gestão da sala de aula, planejamento e execução de atividades, planos de aulas, sequências didáticas, projetos de ensino e atividades de avaliação da aprendizagem dos alunos;

- 2 meses para e elaboração do relatório final, avaliação e socialização dos resultados na escola, na universidade e na comunidade por meio de participação em eventos e publicação de artigos. 
Subprojeto: Relações e inter-relações - diálogo e intervenções do professor em formação - Licenciatura de Educação Física

$O$ presente subprojeto teve por objetivo geral o aperfeiçoamento da relação existente entre teoria e prática dos licenciandos no ambiente escolar, auxiliando a melhoria da qualidade dos cursos de formação inicial e continuada de professores no que se refere às relações e inter-relações, promovendo um ambiente sociomoral nas escola-campo participantes.

Para atingir esse objetivo geral, o subprojeto possuía cinco objetivos específicos, conforme o Projeto Institucional, cadastrado na Plataforma da CAPES - Coordenadoria de Aperfeiçoamento de Pessoal de Nível Superior, a saber:

- Desenvolver um olhar investigativo com coleta de dados e diagnóstico do ambiente escolar no que compete as relações e inter-relações mediante quebra de regras e condutas dos educandos na escola-campo.

- Formar os preceptores e residentes no que tange a aspectos do currículo, compreendendo que os processos de ensino e de aprendizagem deve ser planejado e intencional. Entre os conteúdos da formação devem estar contemplados: plano de aula, projetos didáticos, sequência didática, avaliação da aprendizagem e Base Nacional Comum Curricular.

- Promover reflexão e planos de intervenção nos preceptores e residentes sobre os caminhos, "lições" e mediações diante a quebra de regras e condutas dos educandos na escola-campo que auxiliarão no desenvolvimento de um ambiente sociomoral no espaço escolar.

- Estimular que as práticas pedagógicas dos docentes da escola-campo possam ser revistas, a partir da formação dos preceptores, no que se refere as relações e inter-relações que promovam um ambiente sociomoral na escola.

\section{Percurso Metodológico}

No presente relato, utilizou-se como metodologia as narrativas dos residentes, registradas em diferentes momentos da realização do Subprojeto, fundamentados nos princípios de Creswell (2014) ao considerar que as narrativas se originaram de disciplinas sociológicas e das ciências humanas, 
podendo ser realizadas de muitas maneiras e adotando uma variedade de práticas analíticas.

Dessa forma, delimitamos as narrativas por Bruner (2002, p. 46), "uma narrativa é composta por uma sequência singular de eventos, estados mentais, ocorrências envolvendo seres humanos como personagens ou autores". Nosso relato retrata de forma mais próxima da realidade o que de fato ocorreu no Programa de Residência Pedagógica, portanto, todos considerados como participantes e reais ao processo envolvido.

Bruner (2002, p.69) indica também que sem diminuir a importância da sintaxe, entende que o ser humano "ingressa na linguagem" com "aptidões prélinguísticas para o significado". O teórico faz uma síntese ao afirmar que "nós viemos inicialmente equipados, se não com uma "teoria" da mente, certamente com um conjunto de predisposições para interpretar o mundo social de uma forma particular e para agir sobre as nossas interpretações". Essas compreensões são da maior relevância para pesquisadores que querem dar voz ao pesquisado e desenvolver seus estudos em uma perspectiva êmica, pela complexidade dos participantes no tocante ao envolvimento e fazendo a conexão entre o que desenvolviam na Universidade e experimentavam na escola-campo.

Foram selecionados graduandos do $4^{\circ}$ semestre do curso de Licenciatura em Educação Física de uma universidade particular de Santos SP- UNIMES- para participarem do Programa Residência Pedagógica. Quanto às cinco etapas da participação no Programa, a narrativa de uma residente evidencia a relevância da formação inicial proporcionada pelo Programa ainda no ambiente universitário:

A formação inicial ministrada pelos professores coordenadoras na Universidade foi essencial, pois alguns itens fundamentais ao processo educativo precisariam ser retomados mesmo... Como por exemplo, refletirmos função social da escola, a necessidade da organização, planejamento das ações pedagógicas para que sejam intencionais, compreendermos o que é e quais os objetivos do Projeto Político Pedagógico (PPP), repensarmos algumas as organizações disciplinares do currículo como interdisciplinaridade, pluridisciplinaridade, multidisciplinaridade e transdisciplinaridade, aprendizagem significativa, modalidades organizativas dos processos 
educativos e organização da prática pedagógica em tempo e espaço - como sequência didática e a também a BNCC (Base Nacional Comum Curricular). (sic) [Residente L, grifos dos pesquisadores]

Dessa forma, a formação inicial para o Programa aos residentes compreendeu a função social da escola como formação do cidadão na sua totalidade, ou seja, discutiu direitos e deveres, aspectos emocionais, valores morais, culturais e habilidades, buscando formar um cidadão crítico. Segundo a Lei de Diretrizes e Bases da Educação (BRASIL, 1996), a escola tem como função social formar o cidadão, e, desse modo, garantir as finalidades registradas no artigo 22: "A educação básica tem por finalidade desenvolver o educando, assegurar-Ihe a formação comum indispensável para o exercício da cidadania e fornecer-lhes meios para progredir no trabalho e em estudos posteriores".

Já a temática do projeto político pedagógico, conforme Veiga (2002) refere-se à organização do trabalho pedagógico em dois níveis: como organização da escola como um todo e como organização da sala de aula, incluindo sua relação com o contexto social imediato, procurando preservar a visão de totalidade. Outra temática abordada no PRP foram as organizações disciplinares do currículo: a interdisciplinaridade - existe cooperação e diálogo entre as disciplinas, ação coordenada; a pluridisciplinaridade - é uma temática comum mas tem relação de cooperação; já a multidisciplinaridade - também é uma temática comum, porém sem relação e cooperação entres disciplinas e a transdisciplinaridade - pensamento complexo; transcende a interdisciplinaridade como recurso para práticas educativas inovadoras. 


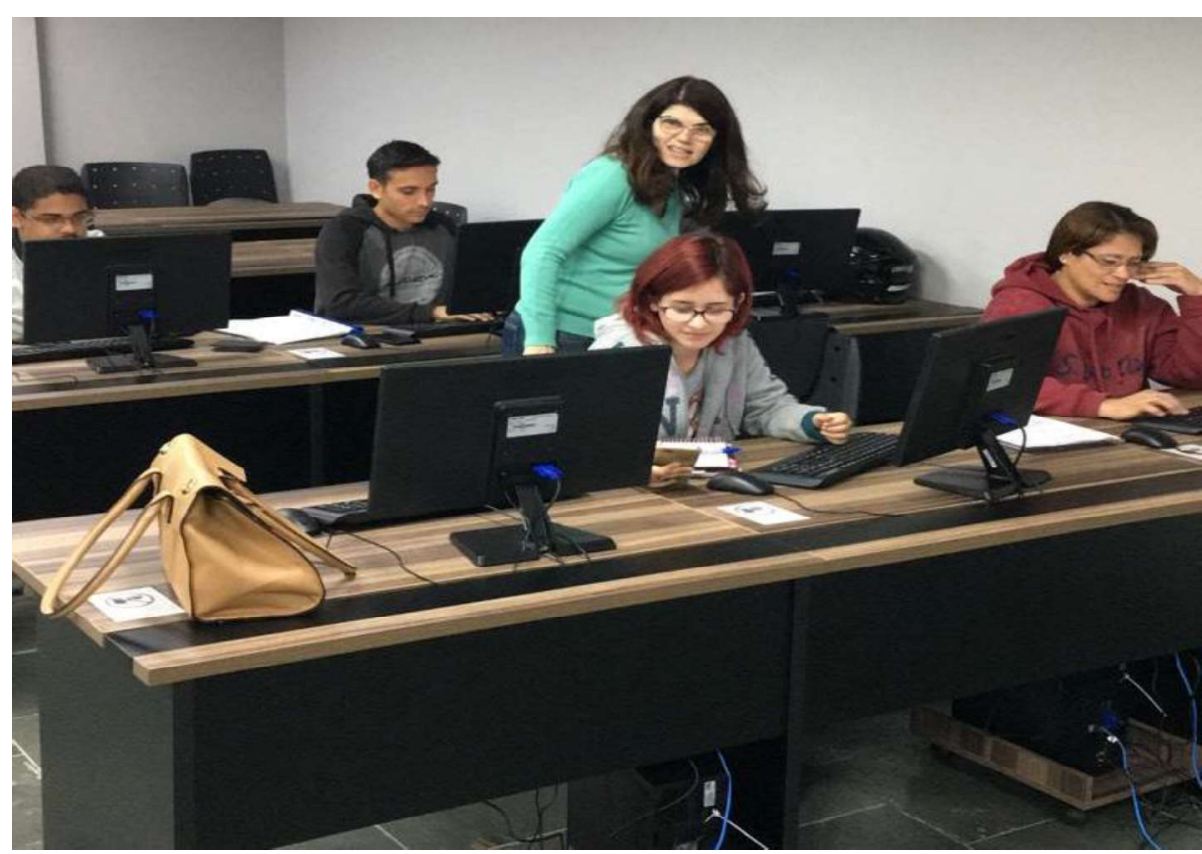

Figura 1 - Etapa de Formação no Programa de Residência Pedagógica Fonte: Relatório dos Residentes do Programa

Na Figura 1, verificamos parte da formação, onde os alunos explicitavam suas ideias acerca do subprojeto no que tange à elaboração do seus respectivos Planos de Atividades do Programa a ser desenvolvidos no interior da Escola-Campo. Alguns espaços diversificados como laboratórios e biblioteca foram utilizados para proporcionar novos desafios no uso de metodologias e estratégias para o ensino que contemplasse o desenvolvimento de competências sociomorais para a melhoria da qualidade das relações e inter-relações no ambiente escolar.

Outra temática trabalhada foram as modalidades organizativas dos processos educativos e organização da prática pedagógica em tempo e espaço - como sequência didática, que é uma das estratégias para desenvolver o aprendizado que tenha diálogo com o projeto curricular da escola, ou seja, é onde o professor por meio dos objetivos que pretende alcançar com seus alunos vai organizar sistematicamente "uma série de atividades para atingir a aprendizagem daqueles conteúdos selecionados para uma determinada 
unidade didática: os conceituais, procedimentais e atitudinais" (ZABALA, 1998, p.18).

A Base Nacional Comum Curricular - BNCC (BRASIL, 2018) é compreendida como um documento de caráter normativo que define o conjunto orgânico e progressivo de aprendizagens essenciais que todos os alunos devem desenvolver ao longo das etapas e modalidades da Educação Básica. Em relação à educação física escolar, destaca que é um componente na área de linguagem, com os aspectos culturais e sociais das práticas corporais que devem ser trabalhados com os alunos - categorizadas em seis unidades temáticas: lutas, danças, jogos e brincadeiras, práticas corporais de aventura, ginásticas e esportes.

Ao longo dos conteúdos trabalhados, foi enfatizada a questão da aprendizagem significativa que é aquela em que as ideias expressas simbolicamente interagem de maneira substantiva e não-arbitrária com aquilo que o aprendiz já tem de conhecimento. Esse conhecimento deve ser relevante e já existente na estrutura cognitiva do sujeito que aprende, Ausubel (2002) destaca que esse fator se chama subsunçor, que permite dar significado a um novo conhecimento que lhe é apresentado ou por ele descoberto.

A ambientação, realizada na Escola-Campo, foi feita por meio de visitas à escola, sendo narrado por uma das residentes dessa investigação que:

Nessas visitas a preceptora fez sua apresentação relatando sua formação acadêmica, seu plano de aula a sua trajetória profissional; também apresentou a estrutura da escola-campo e seu entorno. A professora contou como era a escola quando ingressou, em 2005, as mudanças que foram feitas até os dias atuais e tirou dúvidas dos regentes. Numa das visitas pudemos observar o "Movimento Leia - São Vicente", proposta da Seduc para todas as escolas municipais da cidade, iniciativa que tem como objetivo o incentivo à leitura. Nesse mesmo dia foram entregues os livros didáticos adotados para o ano de 2018. No início da ambientação o núcleo da residência pedagógica onde estagiamos passava por manutenção de pintura e restauração do portão principal da escola. O grupo de residentes realizou durante oito encontros na escola a etapa denominada revitalização. Programamos e realizamos, nos pátios externos e internos da escola, pinturas no chão, de jogos para recreação como: amarelinhas (de vários tipos e tamanhos), raias de corrida, linhas para o desenvolvimento da coordenação motora e um tabuleiro para jogos de dama e xadrez. Em uma das 
paredes do pátio pintamos uma lousa e um jogo da velha. (sic) [Residente M, grifos dos pesquisadores]

A narrativa de $M$ - residente - evidencia a relevância da etapa de ambientação tendo em vista que o reconhecimento do entorno da escola foi importante para conhecer a comunidade, alguns anseios em relação às ações educativas e reflexões críticas acerca de como implementar ações do subprojeto de Educação Física que melhorasse a vida escolar desses educandos.

M também relata o envolvimento com um Projeto Institucional da rede, durante o processo de ambientação já inserida em vivências pertinentes aos atores das atividades educativas da própria instituição de ensino, sendo bastante significativa, pois foi apontada durante a narrativa da etapa desenvolvida.

Figura 2 - Etapa de Ambientação no Programa de Residência Pedagógica

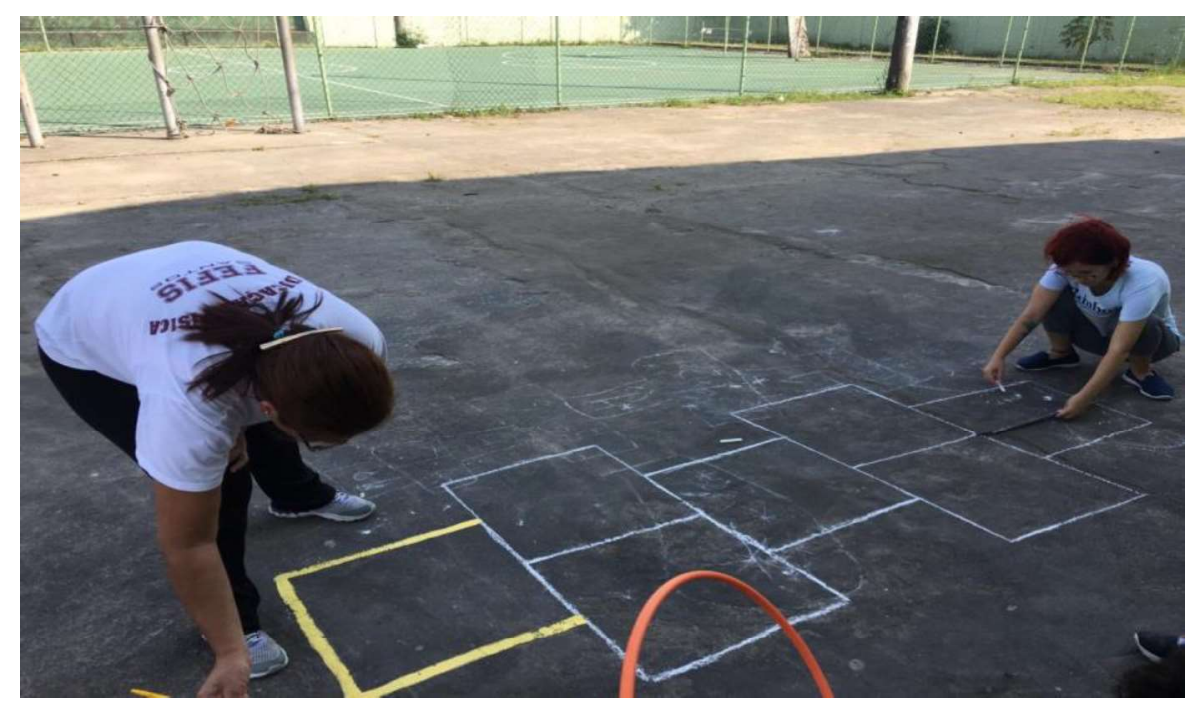

Fonte: Relatório dos Residentes do Programa

$\mathrm{Na}$ Figura 2 há a representação de outro aspecto que envolveu os residentes deste Projeto que foi o de melhorar os espaços escolares utilizados, propondo ações de revitalização de alguns locais que eram subutilizados, mas que eles fizeram algumas pinturas de brincadeiras e jogos para posteriormente utilizarem na regência como forma de desenvolver habilidades relacionadas aos objetivos específicos do subprojeto. 
Durante a etapa da regência, os alunos vivenciaram práticas educativas assistidas pela professora-preceptora e acompanhadas pelos professores coordenadores em ações formativas na universidade e in loco. As experiências foram diversas, onde a residente $L$ indica algumas contribuições da etapa:

A etapa da regência teve início no começo de julho e término no mês dezembro. Nesse período, os residentes alternavam as idas, uns com os outros semanalmente, e em alguns momentos o ia o grupo todo, por conta de eventos na escola ou por pedido da preceptora. Colocou-se em prática as temáticas apreendidas na primeira etapa do Programa, dando ênfase ao planejamento de aula e ao preenchimento dos relatórios. Atuamos em 9 (nove) turmas, sendo elas de: $1^{\circ}$ ano $A / D, 2^{\circ}$ ano $A / B / C / D, 3^{\circ}$ ano $C / B 4^{\circ}$ ano $A / B / C$, totalizando 249 alunos ativos. Trabalhamos nos subprojetos com diversos aspectos, atingindo os objetivos específicos inicialmente colocados por meio de jogos cooperativos, ações educativas solidárias, trabalhos diversos para resgatar valores, solidariedade e compreensão da justiça, equidade, respeito e valorização às diferenças. Além disso, também foram trabalhados os eixos, conforme o currículo municipal prescrito: dança, ginásticas, esportes, brincadeiras e jogos. Percorrendo um trajeto de atividades de brinquedo cantados, a iniciação esportiva. A regência foi indispensável para compreendermos a necessidade do planejamento, da elaboração de atividades com objetivos claros e os registros das atividades, ações desenvolvidas e avaliação da aprendizagem. (sic) [Residente L, grifos dos pesquisadores]

A narrativa de L retrata parte da riqueza do que o Programa de Residência Pedagógica proporcionou à vivência e formação docente inicial desses licenciandos, fazendo uso dos sentidos de alguns conhecimentos teóricos aprendidos em práticas do cotidiano, tais como planejamento, registros escolares, avaliação da aprendizagem, compreensão que os sistemas de ensino possuem diretrizes curriculares que apesar da flexibilidade possível, há um norte a seguir por meio do currículo prescrito. 


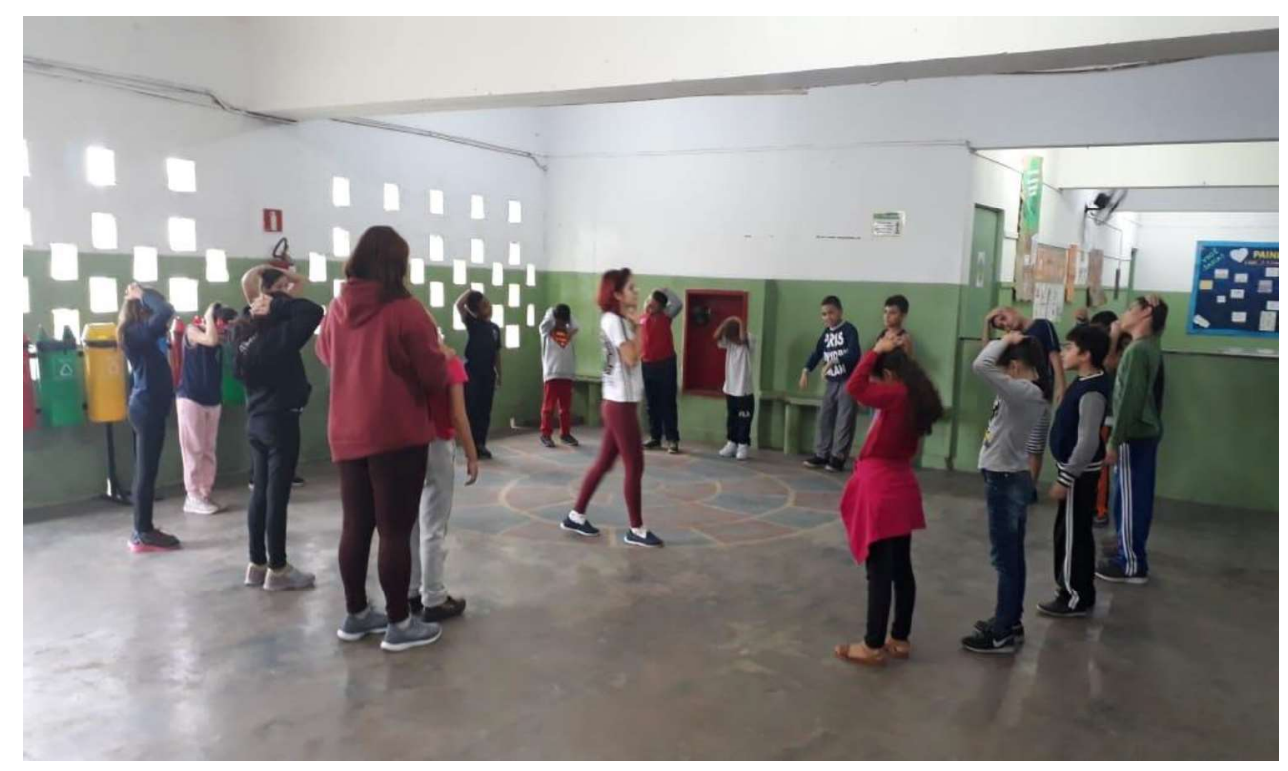

Fonte: Relatório dos Residentes do Programa

A Figura 3 ilustra parte das atividades desenvolvidas na etapa de regência. Nos registros das residentes $\mathrm{L}$ e $\mathrm{M}$ ficou explicitado que os alunos desenvolveram atividades que trabalharam ideias voltadas para a formação cidadã e sociomoral por meio de relações e inter-relações, entre as quais: solidariedade, respeito mútuo, justiça, equidade.

\section{Resultados e Discussão}

Os principais resultados dessa experiência da Regência Pedagógica passam, necessariamente, pela própria vivência da prática da docência, isto é, lidar com a realidade das crianças, da escola, dos pares - equipe - e aprender a lidar com as inseguranças e dificuldades frente a pouca experiência nessa área, conforme percebemos na narrativa da residente:

As etapas de avaliação e socialização foram de extrema relevância, pois tivemos, assim como nas formações ocorridas no decorrer do Programa já iniciado nas escolas, a possibilidade de trocar experiências bem-sucedidas entre os próprios residentes, professora-preceptora e professores coordenadores. Ressalto que para mim, foi bastante gratificante a participação dos dois Simpósios realizados na Universidade. Nesses dois eventos, tivemos a oportunidade de 
sermos ouvidos por diversos alunos, professores e comunidade, alguns participantes do Programa e outros interessados em conhecer um pouco dos nossos resultados. (sic) [Residente M, grifos dos pesquisadores]

Figura 4 - Etapas de Socialização no Programa de Residência Pedagógica

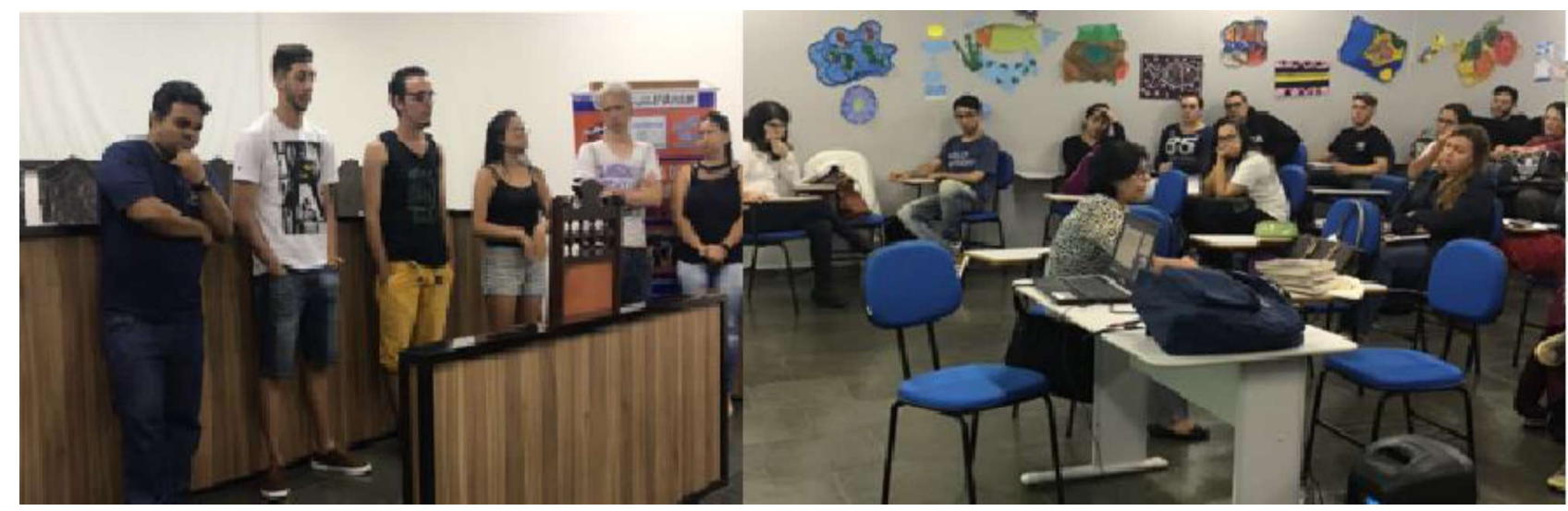

Fonte: Relatório dos Residentes do Programa

A figura 4 indica a participação dos alunos em momentos importantes, conforme a narrativa da residente $\mathrm{M}$, onde os dois Simpósios realizados pela Universidade foi um momento de compartilhar suas experiências vivenciadas, destacar possibilidades para oferecimento de um ensino público voltado para a formação cidadã, além de criar nos residentes o espírito crítico e protagonista por meio de seus relatos de experiências em que se percebe cada vez mais próximo do exercício da docência.

\section{Considerações Finais}

Fazer parte do Programa Residência Pedagógica permitiu conhecer caminhos possíveis para agir como futuros docentes na área da Educação Física. Pode-se observar a realidade escolar e constar que há aspectos positivos e negativos tanto na escola-campo como na relação entre os regentes. Os aspectos positivos a serem ressaltados são: a convivência com as crianças que provocaram uma mudança atitudinal dos regentes, a inclusão dos alunos nas atividades, a professora preceptora que foi participativa e contribuiu para o planejamento das aulas, a Coordenação e demais funcionários foram igualmente colaborativos e elogiaram a revitalização 
realizada, o espaço físico da escola-campo que dá oportunidade de criar várias atividades físicas para realização das aulas e os momentos de reunião com os professores durante as HTPC (Horas de Trabalho Pedagógico Coletivo) e HTPI (Horas de Trabalho Pedagógico Individual) quando era possível uma troca de experiência e diálogo com os demais professores da escola. Os aspectos positivos do grupo de regentes foram: frequência, criatividade e colaboração. Os pontos desafiadores: o grupo de regentes teve, inicialmente, dificuldade para a realização do planejamento e realização das atividades propostas. $\mathrm{Na}$ escola-campo pode-se perceber que no final da regência havia falta de materiais para as atividades, devido ao mau controle dos mesmos.

Ao longo do desenvolvimento dos subprojetos que desenvolvemos de forma orgânica e interativa com as escolas participantes do Município de São Vicente esperamos que os cursos de licenciatura se abram para essa possibilidade formativa e valorizem a vivência dos futuros docentes no contexto das escolas e que os contatos com as novas metodologias inovadoras que o processo de formação, de pesquisa e de troca de saberes poderão propiciar contribuam para a melhoria do processo ensino-aprendizagem e ao mesmo tempo em que articulem de forma significativa teoria e prática e de modo mais amplo, direcionem a formação docente, gestão e pesquisa.

Pensamos que a Residência Pedagógica pode se configurar como espaço privilegiado para a troca de saberes entre os cursos de licenciatura da UNIMES e as escolas de educação básica que participaram do Programa, favorecendo, desse modo, que, nessa teia complexa de circularidade cultural, surjam saberes e conhecimentos que possam ressignificar o processo de formação de professores voltado à reinterpretação dos espaços educativos como produtores de conhecimentos verdadeiramente significativos e emancipatórios. Espera-se ainda que com o desenvolvimento do projeto e com o esperado engajamento dos alunos/residentes e dos professores orientadores da IES, as experiências com a escola - campo criem a necessidade de uma nova diretriz para o Estágio Supervisionado com maior articulação teoria e prática. 
Este por sua vez deve estar articulado ao Projeto Pedagógico dos cursos de licenciatura e com a Proposta Pedagógica das escolas de educação básica que participam do projeto, propiciando a (re)construção do conhecimento do futuro profissional da educação, mediado pela realidade dinâmica das escolas sempre em movimento quase incapturável por olhares despreparados. A par dessas considerações, espera-se que os futuros residentes se envolvam de maneira rica tanto com o processo de construção de conhecimento quanto com o processo de ensino-aprendizagem valorizando tanto saberes locais quanto os de caráter universal e sistematizado, produzindo uma relação de verdadeira imersão em todas as facetas do cotidiano escolar, o que fará dele um profissional reflexivo e transformador comprometido com a formação integral de seus futuros educandos.

\section{Agradecimentos}

Agradecemos à Coordenação de Aperfeiçoamento de Pessoal de Nível Superior - CAPES pelas bolsas concedidas aos 24 residentes, 3 professores preceptores, 1 professor-coordenador e 1 coordenador institucional e à Universidade Metropolitana de Santos - UNIMES pelos investimentos ao Projeto com bolsas de demais recursos.

\section{Referências}

AUSUBEL, D. P. Adquisición y Retención del Conocimiento: una perspectiva cognitiva. Barcelona: Paidós, 2002.

BRASIL. Base Nacional Comum Curricular - BNCC. Disponível em: http://basenacionalcomum.mec.gov.br/. Acesso em: 10 set. 2020.

BRUNER, J. Atos de significação. 2.ed. Trad. Sandra Costa. São Paulo: Artmed, 2002.

CRESWELL, J.W. Investigação qualitativa e projeto de pesquisa. Escolhendo entre cinco abordagens. São Paulo: Penso Editora, 2014.

CAPES. Coordenação de Aperfeiçoamento de Pessoal de Nível Superior. Disponivel em:>http://www.capes.gov.br/perguntas-frequentes. Acesso em: 10 set. 2020. 
FREIRE, P. Pedagogia da autonomia: saberes necessários à prática educativa. São Paulo: Paz e Terra, 1996.

FREIRE, P. Pedagogia do oprimido. Rio de Janeiro: Paz e Terra, 1984.

GATTI, B. A., NUNES, M. M. R. (Orgs.). Formação de professores para o ensino fundamental: estudo de currículos das licenciaturas em pedagogia, língua portuguesa, matemática e ciências biológicas. Textos FCC, São Paulo, v. 29, 2009. Disponível em: http://www.fcc.org.br/pesquisa/publicacoes/textos_fcc larquivos/1463/arquivoAnexado.pdf. Acesso em: $\overline{10}$ set. 2020.

GATTI, B. A. Formação de professores no Brasil: características e problemas. Educação \& Sociedade, Campinas, v. 31, n. 113, p. 1355-1379, out-dez. 2010. Disponível em: https://www.scielo.br/pdf/es/v31n113/16. Acesso em: 10 set. 2020.

VEIGA, IIma, P. A. Projeto Político Pedagógico da escola: uma construção coletiva. 14 ed. Brasília, Papirus, 2002.

ZABALA, A. A prática educativa: como ensinar. Porto Alegre: Artmed, 1998.

\section{Sobre os autores}

\section{Mariana Costa Gama}

macostagama@gmail.com

Licenciada em Educação Física, egressa e residente do Programa de Residência Pedagógica da Universidade Metropolitana de Santos - UNIMES.

\section{Lívia Solange Nery da Silveira}

liviasnery@gmail.com

Licenciada em Educação Física, egressa e residente do Programa de Residência Pedagógica da Universidade Metropolitana de Santos - UNIMES.

\section{Mariangela Camba}

mariangela.camba@unimes.br

Doutora em Educação (Políticas de Avaliação) pela Universidade de Campinas em (2011), Mestre em Educação (educação e Currículo) pela Pontifícia Universidade Católica de São Paulo (2002) e Graduada em Pedagogia pela Faculdade de Ciências, Educação e Letras Don Domênico (1981). Atualmente é docente do Programa de Mestrado Profissional: Práticas Docentes no Ensino Fundamental da Universidade Metropolitana de Santos nas disciplinas Avaliação e as Práticas Interdisciplinares no Ensino Fundamental, Políticas Públicas Implementadas no Ensino Fundamental. Coordenadora do Curso de Pedagogia e Professora em Cursos de Graduação na UNIMES. Coordenadora Institucional do Programa de Residência Pedagógica na Universidade Metropolitana de Santos - UNIMES. 


\section{Elisete Gomes Natário}

elisete.gomes@unimes.br

Doutora em Educação pela Universidade Estadual de Campinas (2001), Mestre em Psicologia pela Pontifícia Universidade Católica de Campinas (1994) e Graduada em Psicologia pela Pontifícia Universidade Católica de Campinas (1988). Atualmente é docente do Programa de Mestrado Profissional: Práticas Docentes no Ensino Fundamental da Universidade Metropolitana de Santos e professora doutora em cursos de graduação. Professora-Coordenadora do Programa de Residência Pedagógica da Universidade Metropolitana de Santos - UNIMES.

\section{Michel da Costa}

michel.costa@unimes.br

Doutor em Educação Matemática pela Universidade Anhanguera de São Paulo - UNIAN(2019), Mestre em Educação Matemática pela Universidade Bandeirante de São Paulo - UNIBAN (2010), Licenciado em Pedagogia pela Faculdade Don Domênico (2003) e Ciências - com habilitação plena em Matemática pela Universidade Santa Cecília - UNISANTA (2000). Atualmente é Supervisor de Ensino efetivo na Prefeitura Municipal de Cubatão e Professor Doutor com Jornada Parcial na Universidade Metropolitana de Santos. Professor-Coordenador do Programa de Residência Pedagógica da Universidade Metropolitana de Santos - UNIMES

\section{Cristina Celia Neri Borges}

crisnerib@gmail.com

Possui graduação em Educação Física pela Universidade Metropolitana de Santos (2001). Desde 2011 atuando como professora de educação básica, disciplina Educação Física, na Prefeitura Municipal de São Vicente. Pós graduada em Jogos Cooperativos pela UNIMONTE. Professora-Preceptora do Programa de Residência Pedagógica em parceria da Prefeitura Municipal de São Vicente com a Universidade Metropolitana de Santos e CAPES. 